\title{
Effectiveness of Audio-Visual Aids with Subsequent Structured Manual Instruction in Anatomy Dissection Hall Teaching
}

Dr. U. L. Gajbe ${ }^{1}$, Dr Aarti Panchbhai ${ }^{2}$, Dr. B. R. Singh*3, Dr. Priti Thute ${ }^{4}$, Dr. Monalisa Roy

${ }^{1}$ Professor and Head, Department of Anatomy, Jawaharlal Nehru Medical College, DMIMS (DU), Sawangi (M), Wardha, Maharashtra, India

${ }^{2}$ Associate Professor ,Department of oral medicine and radiology, Sharad Pawar Dental College, DMIMS (DU), Sawangi (M), Wardha, Maharashtra, India

${ }^{3}$ Associate Professor, Department of Anatomy, Jawaharlal Nehru Medical College, DMIMS (DU), Sawangi (M), Wardha, Maharashtra, India

${ }^{4}$ Associate Professor, Department of Anatomy, Jawaharlal Nehru Medical College, DMIMS (DU), Sawangi (M), Wardha, Maharashtra, India

5Tutor, Department of Anatomy, Jawaharlal Nehru Medical College, DMIMS (DU), Sawangi (M), Wardha, Maharashtra, India

Corresponding Author : drbrijsing@gmail.com

\section{ABSTRACT}

The knowledge of anatomy plays an integral role in the education and practice of health care professionals. Cadaveric dissection is the most reliable method to teach the gross anatomy since centuries. Hands-on-educational experiences on cadavers can also stimulate student interest, increase knowledge retention and enhance development of clinical skills. Common problems faced during anatomy dissection are non-availability of individual instructor for each table, Crowding of students in dissection owing to lack of clear, timely and uniform instructions. Hence, the purpose of our study is to evolve a modality that will increase efficiency of dissection, make it more clinically relevant and make students enthusiastically participate in dissection. This modality will contribute more to overall better understanding of human anatomy within limited time period.

AIM AND OBJECTIVE: To study the effectiveness of audio-visual aids followed by structured manual instruction in dissection hall teaching and to compare the student's learning gain between conventional and modified dissection hall teaching.

OBSERVATIONS AND RESULTS: During the study period two hundred students were present in First MBBS, anatomy department. Out of these all two hundred students fulfilled the inclusion criteria and participated in the study. Mean post test score of study group was $2.84 \pm 1.46$ where as mean pre test score of control Group was3.7 \pm 1 .8showing significant difference. The post test score of the study group was almost double the post test score of control group. This finding is statistically very significant. 
CONCLUSION: Audio-visual aids, structured schedules, and cadaveric dissection were found to be effective in dissection hall teaching in anatomy. It was found to be more effective than conventional method with regard to understanding of the structure, its placement and building of the concepts.

Keywords : Audio-Visual Aid, Dissection Hall Teaching, Modified Dissection Hall Teaching, Cadaveric Dissection, Gross Anatomy Teaching

\section{INTRODUCTION}

The knowledge of anatomy plays an integral role in the education and practice of health care professionals. ${ }^{1}$ The teaching of gross anatomy has for centuries relied on the dissection of human cadavers. $^{2-5}$ Most of the clinical skills and procedures require a thorough understanding of the spatial relationship between adjacent structures of the body. ${ }^{6}$ Hands-on-educational experiences on cadavers can also stimulate student interest, increase knowledge retention and enhance development of clinical skills. ${ }^{7-10}$ Common problems faced during anatomy dissection are non-availability of individual instructor for each tables, Crowding of students in dissection owing to lack of clear, timely and uniform instructions. There is a need to identify a strategy that makes dissection not only interesting but also more purposeful, clinically oriented and contribute more to overall understanding of human anatomy within a limited time period. In certain circumstances, the cadaveric dissection may not be an ideal tool for learning anatomy and can be replaced by or enhanced by tools like videos of cadaveric dissection or animated pictures. ${ }^{11,12}$ Viewing the video clips in anatomy among medical students has been reported to improve on comprehension of theoretical knowledge and aid in long term memory retention in them. ${ }^{13,23}$
Hence, the purpose of our study is to evolve a modality that will increase efficiency of dissection, make it more clinically relevant and make students enthusiastically participate in dissection. This modality will contribute more to overall understanding of human anatomy within limited time period. Provision of structured schedules will also bring about objectivity and uniformity in dissection hall teaching. We hope that the modality can foster learning by having its role in affective domain, whereby it will engage learner interest and sustain motivation and ensure learners that there is uniformity in instructions on all dissection tables.

\section{AIM:}

To study of the effectiveness of audio-visual aids followed by structured manual instruction in dissection hall teaching.

\section{OBJECTIVES:}

1) To sensitize students and faculty about modified dissection hall teaching using audiovisual aids. 2) To assess student's performance or learning gain using conventional dissection hall teaching and modified dissection hall teaching using $\mathrm{A}-\mathrm{V}$ aids 3) To compare the student's learning gain between conventional and modified dissection hall teaching. 


\section{METHODS AND MATERIAL}

The present prospective study was conducted in Department of Anatomy, Jawaharlal Nehru Medical College, Sawangi, (Meghe), Wardha in collaboration with SHPER current academic year 2015-16.

Type of study: Non-randomized control study

Ethical clearances: Institutional Ethic Committee duly approved the study vide letter no. DMIMS(DU)/IEC/2014-15/968,Dated 15/12/2014

Duration of study: The study duration was one year during the period from $1^{\text {st }}$ January 2015 to $31^{\text {st }}$ December 2015. Inclusion criteria: All 200 student of 2015 batch admitted in $1^{\text {st }}$ MBBS

1. The conventional method of dissection hall teaching:

The students are divided into twenty groups with ten students in each table. Two tables are allotted to one teacher. During dissection teacher delivers verbal instructions and then students do dissection by following steps given in Cunningham's manual. In case they find any difficulty, teachers guide them to find that particular structure.

\section{The method for modified dissection hall teaching} using audio-visual aids:

The study commenced by preparation of structured manual, audio-visual aids/video for dissection hall teaching, pre-test post-test questionnaire and observer's check list.

\section{Methodology:}

The faculty and students were sensitized and introduced the concept of modified dissection hall teaching. They were also sensitized regarding use of audio visual aids. All students willingly participated in the study and informed written consent was obtained from all the students from study group. (Annexure II).
Didactic lecture on thyroid region was taken for all 1st-MBBS 200 students. After that, validated pre-test of all 200 students was conducted. Then the students were divided into 2- batches of 100 each by convenience sampling into study group and control group. Following this, audio-visual aid of 20 minutes duration was projected in the E-museum to the study group. This was followed by provision of structured dissection manuals to the study group and dissection in a two hours dissection class. Instructions by the table teachers were given as per the dissection steps given in the manual on all the tables of study groups. This maintained uniformity in instructions on all tables. At the end of dissection class, teachers ensured that the students have seen all relevant structures.

This was followed by post test. The conduction of pre test and post test was observation- based. Check list was provided to the faculty during the process and were asked to give marking according to the structures identified.

Dissection class for the control group was conducted by conventional method using Cunningham's manual for dissection. They were also exposed to post-test.

Both control and study groups had equal number of total hours available for dissection and equal time duration for self study, due care was taken in this area. The students of control group were also exposed to new modality and their perceptions were also obtained. There were no dropouts from the study.

\section{Data analysis and statistics:}

The study included two hundred students from First MBBS 2015 batch, and it was conducted in department of anatomy.

The study was evaluated by comparing pre and posttest scores of both study group and control group. 
Evaluation of the study was according to Kirkpatrik's model. The quantitative data obtained by pre and post-test scores for two groups was compared using unpaired " $\mathrm{t}$ " test. Paired t-test was also used for comparing the pre and post-test scores of individual group .For this demo version of software GraphPad InStat was used. [GraphPad Software Inc, San Digeo, USA].

\section{RESULTS AND DISCUSSION}

\section{OBSERVATIONS \& RESULTS:}

During the study period two hundred students were present in First MBBS, anatomy department. Out of these all two hundred students fulfilled the inclusion criteria and participated in the study.

\section{PRE TEST AND POST TEST SCORE}

\begin{tabular}{|l|l|l|}
\hline & Study group & $\begin{array}{l}\text { Control } \\
\text { Group }\end{array}$ \\
\hline $\begin{array}{l}\text { Mean pre test score } \pm \\
\text { standard deviation }\end{array}$ & $2.84 \pm 1.46$ & $2.75 \pm 1.2$ \\
\hline $\begin{array}{l}\text { Mean post test score } \pm \\
\text { standard deviation }\end{array}$ & $6.58 \pm 1.44$ & $3.7 \pm 1.8$ \\
\hline
\end{tabular}

Table 1. Shows the mean pre and post test scores of study and control Groups

Mean pre test score of study group was $2.84 \pm 1.46$ where as mean pre test score of Control Group was $2.75 \pm 1.2$ showing no significant difference. Mean post test score of study group was $2.84 \pm 1.46$ where as mean pre test score of control Group was $3.7 \pm 1.8$ showing significant difference. (Table no. 1) The post test score of the study group was almost double the post test score of control group. This finding is statistically very significant.

\section{ABSOLUTE LEARNING GAIN}

It is to know the learning gain of the students in comparison to the maximum score.

The absolute learning gain was calculated for study and the control group by using the following formula: Absolute learning gain $=\{$ (Post test score - Pre test score)/Maximum score x 100

\begin{tabular}{|c|l|l|}
\hline \multirow{2}{*}{$\begin{array}{c}\text { Absolute } \\
\text { learning gain (\%) }\end{array}$} & Study group & Control Group \\
\cline { 2 - 3 } & $37.4 \%$ & $9.5 \%$ \\
\hline
\end{tabular}

Table no. 2 shows the absolute learning gain for the study group was $37.4 \%$ whereas the absolute learning gain for control group was $9.5 \%$. This observation is displayed in the form of a bar diagram in Graph no.1. Interpretation - This test interprets the learning gain of the students in comparison to the maximum score of the test $37.4 \%$ and $9.5 \%$ for the study and Control group respectively and it is significant.( Table no. 2, Graph no.1 )

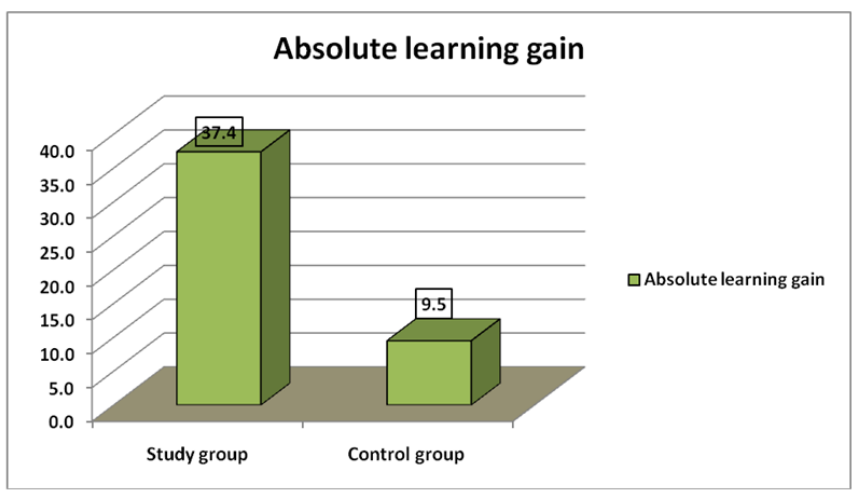

Graph 1 : Bar diagram showing 'Absolute learning gain' score of Study and Control group. 


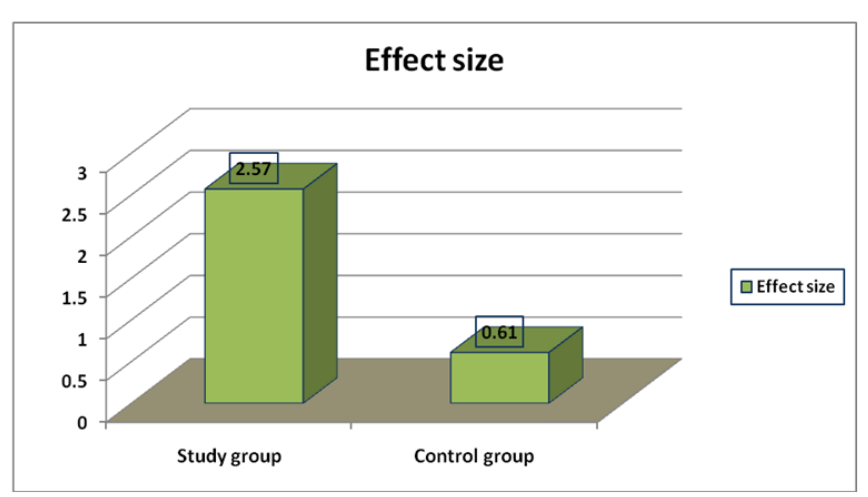

Graph 2: Bar diagram showing 'Effect size' of Study and Control group.

\section{RELATIVE LEARNING GAIN}

It is to know the learning gain of the students in comparison to the pre test score.

The relative learning gain was calculated for study and the control group by using the following formula: Relative learning gain $=\{($ Post test score - Pre test score) / Pre test score $\mathrm{x} 100$

\begin{tabular}{|l|l|l|}
\hline \multirow{2}{*}{$\begin{array}{l}\text { Relative learning } \\
\text { gain (\%) }\end{array}$} & Study group & Control Group \\
\cline { 2 - 3 } & $131 \%$ & $34.5 \%$ \\
\hline
\end{tabular}

Table no. 3 shows the relative learning gain for the study group was $131 \%$ whereas the absolute learning gain for control group was $35.5 \%$.

Interpretation - The learning gain of the students in comparison to the pre test score of the test is 131\% and $34.5 \%$ for the study and Control group respectively and it is very significant.( Table no. 3 )

\section{EFFECT SIZE}

It is the way to measure the effectiveness of a particular intervention

The effect size was calculated by using the following formula: Effect size=Post test score - pre test score/Avg. spread of std. deviation

\begin{tabular}{|l|l|l|}
\hline \multirow{2}{*}{ Effect size } & Study group & $\begin{array}{l}\text { Control } \\
\text { group }\end{array}$ \\
\cline { 2 - 3 } & 2.57 & 0.61 \\
\hline
\end{tabular}

Table no. 4 shows the effect size for the study group and the control group and the values are 2.57 and 0.61 respectively. These observations are displayed in the Graph no.2.

Interpretation: - Effect size is way to measure the effectiveness of a particular intervention. Effect size of the study group is 2.57 i.e. much more than that of the Control group (0.61). Hence, it can be concluded that the intervention is more effective than traditional approach. (Table no. 4, Graph no.2)

\section{Plan of Work}

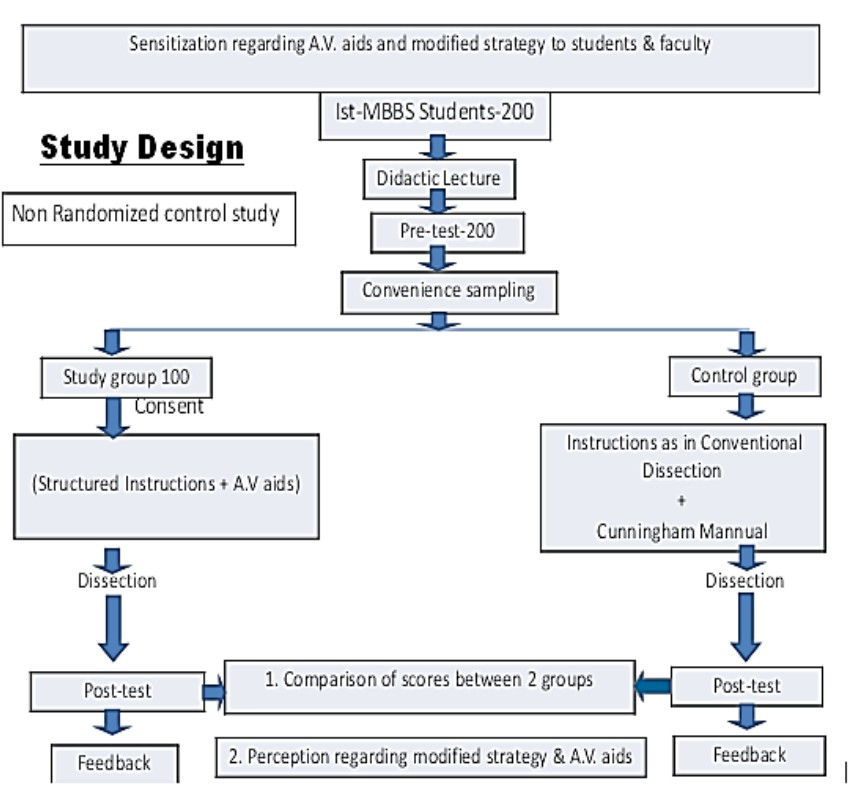

\section{DISCUSSION:}

The traditional anatomy education based on structural anatomy taught through didactic lectures and complete dissection of the body guided by teacher has been replaced by many new teaching tools. In this era, where methods and time dedicated for teaching human anatomy are changing, it compels 
anatomists to add effective teaching modalities for the medical students.

During our teaching experience in medical school for nearly two decades and from informal feedback from students, we have observed that students on different dissection tables are taught by different teachers with disparity in their instructions. To bridge this gap there is a need to design structured schedules and audio visual aids which will bring about objectivity and retain uniformity in dissection hall teaching.

The results of the work by Machado JA (2013) highlighted the value of imaging anatomy in learning human anatomy. Students' comments pointed out a need to focus teaching/learning programs toward a more practical rather than theoretical approach. In order to provide an optimal learning environment to students, it also seemed important to create improved media material as an additional resource tool. ${ }^{11}$ In our study group $66 \%$ students commented that it will help to perform better in clinical posting period.

In the study by Chapman SJ et al (2013), 170 students (71\%) responded to the survey. Overall, dissection was the single highest scored method, followed by prosection. Newer approaches such as models, computer software packages and living \& radiological anatomy scored comparatively worse. The most suitable method for achieving individual learning objectives was variable with dissection perceived as most suitable for four out of nine objectives. ${ }^{12}$ This is also reflected in our study that audio visual aid and structured schedule in dissection proved to be most suitable modality as perceived by the $86 \%$ students of the study group.

The faculty of anatomy at University of north Texas Health sciences centre (UNTHSC) had developed computer based dissection manual to adjust with their curricular changes and their time constraints. Even with strong priority and importance to the computerization of anatomy lab, they gave utmost importance to cadaveric dissection. R Bhatnagar et al (2013) reported that the time constraints had compelled the traditional teacher to only teach anatomy that was going to be clinically relevant to them in their subsequent practices. The dissection room teaching when complimented by structured tests would make the student focused for learning and enthusiastically participate in dissection within the given time frame which reflects from this study that $71 \%$ students agreed with the fact. ${ }^{14}$

The current crop of medical students is techno-savvy whose major part of the day is broadly influenced by visual and auditory communication. These undergraduate prefer animations over and above text books and however anathema it may seem to educator, this preference should be respected and incorporated in instructions to get the results. ${ }^{15}$

Rustin E. et al (2004) reported that the computer is a perfect medium for the delivery of complementary educational aids in Anatomy, such as cross sectional Anatomy and digital images of prosected cadaveric structures, as well as a highly efficient means of portraying dissection procedures linked to anatomic images. ${ }^{16}$ This is comparable to our study in which $87 \%$ of the students agreed that audio visual aids should be there with the traditional teaching for dissection hall teaching.

Satendra Singh et al (2009) from their study on teaching styles and approaches have reported that the students disliked both Transparencies \& Power Point slides for the monotony of the classes \& lack of interest it generates among both the teacher \& the students. Whereas Animation based lecture (ABL) was maximally accepted by students \& majority of 
students agreed that Animation based lecture (ABL) helped to sustain interest, visualize concepts better, remembering facts, applying knowledge and understanding facts better. ${ }^{17}$ Animations base lecture is similar to the Teaching Learning modality used by us. In our study, we have got similar findings in favors of the use of audio visual aids.

Snigdha Mishra et al(2014) in their study in their study titled "Impact of noval method of teaching Anatomy of male perineum on undergraduate medical students," used the video recording of the dissected perineum, 2D images and 3D models to teach anatomy of perineum. They compared the effectiveness of this method with the traditional method of verbal teaching of dissection and found that the digital anatomical teaching tool i.e. video recording of dissection, 2D images and 3D models was very effective and enhances the understanding of the students. ${ }^{18}$ In our study, we have got the similar findings. We have used the dissection video recording of thyroid region with commentary prior to the beginning of the dissection class. It was appreciated by $84 \%$ of the study group students and reported that the study material and structured schedule were very effective and it was very useful for retention of the topic, to understand the steps, procedure of the dissection and the locations of the structures better.

Sushil kumar and R. K. Zargar (2014) subjected the students for few tests and the tabulated learning objectives for the dissection during week were put up on notice board. It was observed that the students started taking active part in dissection. It gave the students an impetus to do better in the next test. The under achiever started asserting themselves. Outcome of each dissection were neat and better exposed structures. Each dissection was purposeful. The keenness to learn about the clinical aspect was the driving force to enter the dissection hall with enthusiasm and met the learning objectives which are comparable with the importance of structured schedule and learning gain. ${ }^{19}$

According to Lewis T. L. et al (2014) the strength of tablet technology lies in its ability to consolidate and present anatomical information to the user in the most appropriate manner for their learning style. The only question mark remains over the level of detail and accuracy of these applications. Innovative medical educators who embrace tablet technology will find that anatomy applications serve as a useful learning tool when used in conjunction with existing teaching setups, ${ }^{20}$ which holds true for the present study also where $86 \%$ students agreed with the fact.

Lastly, the lecture effectiveness depends upon the teachers' skill like communicational skills, gesture, voice, handling of the subject and command over the language. Good communication skills are required that facilitate students to communicate effectively with one another. ${ }^{21}$ Therefore whatever mode of instruction the teacher is using, his /her own personal abilities of verbal oration and oral teaching play a important role in educating the students and transferring the essence of a topic to them. ${ }^{22}$ And if the teachers are not with the good communication skills, one of the way to dispense knowledge to the students in a effective way is audio visual aids and other technologies.

By conduction of the modality framed, we believe that the expected outcome would account for dividing the entire body dissection into the required number of structured schedules. The students remained focused because the schedule has specific learning objectives. The dissection of the part to be dissected was systematically done and the result of dissection was improved. The students started taking genuine interest which started lively academic 
dissection in the dissection hall. To the best of our knowledge and literature search, we could not find any one study that combined real cadaveric dissection, audio visual aids and structured schedules, for the better understanding of the orientation of the structure in the body.

\section{SUMMARY:}

The amplitude of Teaching/Learning in dissection hall is fairly wide and within the time constraint, the teacher is compelled to be skimpy. The purpose of our study is to evolve a modality that will increase efficiency of the dissection, make it more clinically relevant and make students enthusiastically participate in dissection. This modality will contribute more to overall understanding of human anatomy within limited time period. Provision of structured schedules will also bring about objectivity and uniformity in dissection hall teaching. The improvement in the knowledge, was assessed in both groups study and control group by comparing pretest and post-test scores. The mean score of study \& control group was compared by unpaired' $t$ ' test \& paired' $\mathrm{t}$ ' test.

Overall to conclude, the modality was well accepted by the students. In order to provide optimal learning environment to students it is important to create improved multimedia material as an additional resource to utilizing new modalities in dissection hall teaching. In coming years each university in each discipline would modify, change and evolve a pattern that would bring in uniformity and objectivity in conduction of dissection classes.

\section{IV.CONCLUSION}

Audio-visual aids, structured schedules, and cadaveric dissection were found to be effective in dissection hall teaching in anatomy. It was found to be more effective than conventional method with regard to understanding of the structure, its placement and building of the concepts.

\section{LIMITATIONS OF THE STUDY}

Preparing audio-visual aids may be difficult with regard to time constraint and availability of trained multimedia technocrat.

\section{VI.RECOMMENDATIONS}

> Audio-visual aids, structured dissection schedule and cadaveric dissection in combination should be regularly utilised as a teaching learning method in dissection hall teaching for first MBBS students.

$>$ It should be utilised in other disciplines also.

$>$ There should be arrangement of Kiosk for repeated reference on all dissection tables.

$>$ Each university/Institutions should modify, change and evolve a modality that would bring uniformity and objectivity in conduction of dissection classes.

\section{VII.REFERENCES}

[1]. Sergovich A, Johnson M, Wilson T.D, Explorable Three Dimensional Digital Model of the Female Pelvis, Pelvic contents, and Perineum for Anatomical Education; Anat. Sci. Educ. 2010 3:127-133

[2]. Williams AD, Greenwald EE, Soricelli RL. Depace DM., Medical students' reactions to anatomic dissection and phenomenon of cadaver naming. Anat Sci Educ. 2014 May-Jun; 7(3):169-80. doi: 10.1002/ase.1391. Epub 2013 Aug 1.

[3]. Garg AX, Norman G, Sperotable L., How medical students learn spatial anatomy. Lancet 2001; 357:363-364. 
[4]. Keim Janssen SA, vander Meulen SP, Shostrom VK, Lomneth CS., Enhancement of anatomical learning and developing clinical competence of first-year medical and allied health profession students. Anat Sci Educ. 2014May-Jun; 7(3): 181-190.

[5]. Mahmud W, Hyder O, Butt J, Aftab A., Dissection Videos Do Not Improve Anatomy Examination Scores Anat. Sci. Educ. 2011; 4:1621.

[6]. Percira JA, Meri A, MasdeuC, Molina-Toma's MC Marti-neg-Carrlo A.,Using video clips to improve Theoretical anatomy teaching- Eur. J. Anat.2004; 8:143-146.

[7]. Mc Garvey MA, Farrell T, Conroy RM, Kandiah S, Monkhouse WS., Dissection: a positive experience. Clinical anatomy. 2001May; 14(3):227-230.

[8]. Ellis H., Teaching in the dissecting room. Clin. Anat. 2001 May; 14(2):149-51.

[9]. Reeves RE, Aschenbrenner JE, Wordinger RJ, Roque RS, Sheedlo HJ., Improved dissection efficiency in the human gross anatomy laboratory by the integration of computers and modern technology. Clin. Anat. 2004 May;17(4):337-44

[10]. Sehirli US, Saka E, Sarikaya O., Attitudes of Turkish anatomists toward cadaver donation. Clin. Anat. 2004 Nov; 17(8):677-81.

[11]. Machado JA, Barbosa JM, Ferreira MA., Student perspectives of imaging anatomy in undergraduate medical education. Anat. Sci. Educ. 2013 May-June;6(3):163-9

[12]. Chapaman SJ, Hakkem AR, Marangoni G, Prasad KR., Anatomy in medical education: perceptions of undergraduate medical students. Annals Anatomy 2013; 195 (5): 409-414.

[13]. Rishi Pokhrel, use of audio visual aids in dissection hall. Poster presented at 60th
National conference of Anatomical society of India at Cuttack.

[14]. Bhatnagar R, Pokhrel R, Tandon A., Redeeming dissection course for medical undergraduates by compact structured schedules and frequent incourse assessments. OA Anatomy 2013 Oct 23; 1(3):26.

[15]. O'Day DH., Animated Cell Biology: a quick and easy method for making effective highqualityteaching animations.CBE Life Sci Educ 2006; 5:255-63.

[16]. Rustin E. Reeves, John E. Aschenbrenner, Robert J., Wordinger, Rouel S. Roque, and Harold J. Sheedlo. Improved Dissection Efficiency in the Human Gross Anatomy Laboratory by the Integration of Computers and Modern Technology. Clin. Anat. 2004; 17:337-344.

[17]. Satendra Singh, Savita Singh, Shikha Gautam., teaching styles and approaches: medical student's perceptions of animation-based lectures as a pedagogical innovation Pak J Physiol 2009;5(1):16-19.

[18]. Snigdha Mishra, SatheeshaNayak B. \&Bincy M. George. Impact of A Novel Method Of Teaching Anatomy Of The Male Perineum On The Undergraduate Medical Students. NUJHS. 2014; 4(1): 99-103.

[19]. Sushil Kumar, R.K. Zargar., Redeeming of Discussion an Evolving a Strategy to Bring in Objectivity and Uniformity in Practical Examination in Anatomy. Indian Journal of Anatomy 2014 JAN-Mar; 3(1):23-27.

[20]. Lewis TL, Burnett B, Tunstall RG, Abrahams $\mathrm{PH}$., Complementing anatomy education using three-dimensional anatomy mobile software applications on tablet computers. Clinical Anatomy 2014; 27(3):313-320.

[21]. Prasanna C, Das B. Study of student attitudes towards the use of different types of Audio- 
visual techniques for biochemistry. Research Journal of Pharmaceutical, Biological and Chemical Sciences. 2012 April; 3(2); 1097-1102.

[22]. Suhaib Haider Naqvi, Fizza Mobasher, Mujammad Abdul, Muhammad Umair, AroojNaeemKohli., Effectiveness of teaching methods in a medical institute: perceptions of medical students to teaching aids. Journal of Pakistan medical association. 2013; 14(2): 491508.

[23]. 'Evaluation of 'Audio Visual Aids in Dissection Hall Teaching'. Poster presented at 60th National conference of anatomical society of India at Cuttack 2014.

\section{Cite this article as :}

Dr. U. L. Gajbe, Dr Aarti Panchbhai, Dr. B. R. Singh, Dr. Priti Thute, Dr. Monalisa Roy, "Effectiveness of Audio-Visual Aids with Subsequent Structured Manual Instruction in Anatomy Dissection Hall Teaching", International Journal of Scientific Research in Science and Technology (IJSRST), Online ISSN : 2395-602X, Print ISSN : 2395-6011, Volume 6 Issue 2, pp. , March-April 2019. Available at doi : https://doi.org/10.32628/IJSRST196235 Journal URL : http://ijsrst.com/IJSRST196235 